\section{Oral Contraceptives and Thromboembolic Disease}

Sir,-Dr. J. Selwyn Crawford (11 May, p. 366) questions the conclusion that our study of thromboembolic disease in young women provides " . . . no suggestion . . . that venous thromboembolism tends to occur shortly after beginning the use of oral contraceptives." He suggests that this statement is incompatible with our observation that $42 \%$ (11 out of 26 ) of the women who developed thromboembolic disease and who were using oral contraceptives had been taking them for less than six months. If, however, the experience of the control women who were using oral contraceptives is also taken into account-4 out of 10 of whom had been using them for less than six months -we cannot see how these data can lead to any other conclusion.

It was noted by the Food and Drug Administration ${ }^{1}$ that most of the reported deaths from thromboembolic disease associated with the use of oral contraceptives occurred within the first four months of administration, but it was also pointed out that this might well have been due to the differential reporting of events which occur soon after a new drug is prescribed. We agree that more information on this important aspect of the relationship between the use of oral contraceptives and venous thromboembolic disease is required, and this is one of the principal reasons why we are at present collecting information for the year 1967 to add to that for the years 1964-66.

Dr. Selwyn Crawford also asks, if the 11 cases of thromboembolism (not 10, as stated in his letter) occurring within six months of starting oral contraceptives are disregarded, do the remaining 15 cases constitute a significantly high incidence of the disease ? The answer is yes. The appropriate comparison is then between 15 of 47 affected patients and 6 of 112 controls, and a difference of this magnitude would be expected to occur by chance less often than once in a thousand times.-We are, etc.,

\section{P. Vessey.} R. DOLL.

\section{Medical Research Council's \\ Statistical Research Unit, \\ University College Hospital Medical School}

\section{REFERBNCB}

- Food and Drug Administration Report on the Oral Contraceptives, 1966. Advisory Committee U.S.A.

\section{Cardiac Catheterization in Cardiac Infarction}

SIR,-Is cardiac catheterization a necessary or desirable investigation in acute cardiac infarction? Should this procedure be regarded as a routine investigation in cardiac units? These questions are even more apposite when the cardiac catheterization is not confined to the right side of the heart but includes also the left. The following recent publications have prompted me to raise this question.

Kirby et al.' reported their findings on two patients with acute myocardial infarction. The first patient had cardiac arrest during transport to hospital but responded to mouth-to-mouth respiration and external cardiac massage. When he arrived in hospital he had two bouts of ventricular fibrillation necessitating D.C. countershock. Then one catheter was passed via a femoral vein into his right atrium and another via the femoral artery into his left ventricle. Respiratory function tests were also done. $\mathrm{He}$ was described as "pale and semiconscious" when these tests were done. The other patient submitted to the same procedure was "pale, sweaty, and confused."

MacDonald et al. ${ }^{2}$ reported the passing of three cardiac catheters, one into the pulmonary artery, another into the right atrium, and a third into the thoracic aorta on eight patients with recent cardiac infarction, one of whom was severely shocked and another was aged 79. The purpose of this experiment was to investigate the value of heroin in coronary thrombosis, and, for reasons not fully explained, the heroin was given directly into a heart chamber. The same authors ${ }^{3}$ have also described an exactly similar experiment on another eight patients with recent cardiac infarction (one aged 70), but using pethidine instead of heroin.

A group of doctors from Hammersmith Hospital described cardiac catheterization on 26 patients with acute myocardial infarction (age range 40 to 87 ). One patient was studied twice during successive infarcts. The special point of the investigation was that the cardiac catheter was left in situ in either the pulmonary artery or the right atrium for nine days, and to allow this to be done each had an infusion of one litre each day during this period.

If cardiac catheterization is not a routine procedure in coronary thrombosis then it must be deemed outside normal practice and thus experimental, and then special permis sion must be obtained after full explanation. This very question was posed in your section "Any Questions?" (1 July 1967, p. 37) and the following reply was given:

"In the vast majority of patients there is no indication for intracardiac catheterization after a myocardial infarction. Very occasionally, however, the question of surgical treatment of a complication such as a ruptured interventricular septum or mitral incompetence (due to malfunction of the papillary muscles) may arise. Under these circumstances cardiac catheterization and angiocardiography might well have to be performed to confirm the nature of the complication and to determine its severity." $-\mathrm{I}$ am, etc.,

London W.1.

M. H. PAPPWORTH.

REPERENCBS

Kirkby, B. J., McNichol, M. W., and Tattersfield, Anne, Lancet, 1968, 1, 944.

MacDonald, H. R., Rees, H. A., Muir, A. L. Lawrie, D. M.,' Burton, J. L., Muir, A. L Lonald, K. W., Lancet, 1967,1 , 1070

MacDonald, H. R., Rees, H. A., Muir, A. L.,
Lawrie, D. M., Burton, J. L., and Donald, K. W. Lancet, $1967,2,863$.

Fluck, D. C., Valentine, P. A., Treister, B.,

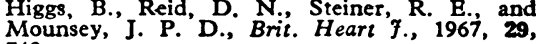
748.

S Brit. med. F., 1967, 3, 37.

\section{Electric Convulsion Therapy}

SIR,-We must assume that your leading article (25 May, p. 448) was not written by a psychiatrist.

In spite of the advent of the tranquillizers, E.C.T. is still widely used in the treatment of schizophrenia, and in some cases is the treatment of choice.-We are, etc.,

\section{MARY MORISON.}

H. R. GeORGR.
Banstead Hospital Surton.

\title{
Asbestos Bodies
}

SIR,-Your correspondents, Dr. W. J. Smither, of Cape Asbestos Company (6 April, p. 51), and Dr. H. C. Lewinsohn, of Turner Brothers Asbestos Company (13 April, p. 120 ), are correct in pointing out that I have no direct evidence that the "asbestos bodies" which I found in lung smears actually contain asbestos fibres (9 March, p. 614). The same criticism can be made of all similar previous studies. However, there is little evidence to support the suggestion that the bodies were produced by any of the alternative minerals proposed by Dr. Lewinsohn.

The bodies formed after inhalation of coal or graphite dust show a black central fibre or spicule, typical of the well-known "pseudoasbestos body," and such structures were specifically excluded from consideration in my survey.

As Dr. Lewinsohn admits, the bodies formed after exposure to talc dust may well be true asbestos bodies, formed from fibres of tremolite or anthophyllite in the talc, but when these are found in the lungs of talc workers they are accompanied by large amounts of doubly refractile dust particles. ${ }^{12}$ None of the histological sections of lung in my series showed such accumulations. Since tremolite is usually present in talc only in small amounts, it is unlikely that a patient could inhale enough asbestos in this way to form detectable numbers of asbestos bodies without at the same time accumulating considerable amounts of talc dust in the lungs.

Formation of asbestos-like bodies has been demonstrated in experimental animals following inhalation of glass fibre, but it is by no means a consistent finding, in contrast with experimental asbestosis in susceptible species. Thus Schepers" and Gross et al.," make no 